\begin{tabular}{|c|c|c|}
\hline $\begin{array}{c}\text { Evaluation of the Water Masses Mixing } \\
\text { Process in the Area of Danube River } \\
\text { Discharge }\end{array}$ & $\begin{array}{c}\text { "Cercetări Marine“" } \\
\text { Issue no. 51 }\end{array}$ & \\
$\begin{array}{c}\text { (Elena Vlăsceanu, Eugen Rusu, } \\
\text { Răzvan Mateescu) }\end{array}$ & Pages 14- 26 & $\mathbf{2 0 2 1}$ \\
\hline \multicolumn{2}{|c|}{ DOI:10.55268/CM.2021.51.14 } \\
\hline
\end{tabular}

\title{
EVALUATION OF THE WATER MASSES MIXING PROCESS IN THE AREA OF DANUBE RIVER DISCHARGE
}

\author{
Elena Vlăsceanu ${ }^{1}$, Eugen Rusu ${ }^{2}$, Răzvan Mateescu ${ }^{1}$ \\ ${ }^{1}$ National Institute for Marine Research and Development "Grigore Antipa”, \\ 300 Mamaia Blvd, 900581, Constanta, Romania \\ 2 "Dunărea de Jos" University of Galati, Faculty of Engineering, \\ 47, Domneasca Street, 800008, Galati, Romania \\ E-mail: evlasceanu@alpha.rmri.ro
}

\begin{abstract}
A series of results of data analysis is presented in this paper, carried for the 2020-2021 marine hydrological cycle. The method included the collection, processing, analysis and archiving of data sets (and information) recorded in the field and obtained from remote sensing (satellite data). The data was required to evaluate the hydrodynamic processes in the coastal/marine area, including the mouths of the Danube, the natural promontories, and marine obstacles such as the ports jetties. Data were collected during the oceanographic expeditions carried over June 2020 and July 2021, on the spatial extension of the Romanian coastal monitoring network. Measurements of physical, chemical, and hydrological parameters were performed in the areas of Sulina, Sf. Gheorghe, Sahalin in order to observe and evaluate the mixing phenomenon of water masses in the area of Danube discharge.

The analysis of the physical and chemical parameters, associated with the hydrological parameters, were emphasizing the influence of the coastal water masses dynamics on the mixing processes afferent to the Danube Delta's offshore areas, due to the physiographic and hydro-morphologic characteristics of an asymmetric delta.
\end{abstract}

Key-Words: Danube discharge, water masses, hydrodynamic processes, ADCP measurements.

\section{AIMS AND BACKGROUND}

For the study of dynamics and interactions between natural hydromorphological factors associated with the vertical mixing processes of water masses in the area of river discharge and also in the proximity of marine obstacles (barrier island, channel jetties), large sets of geospatial data are required: information's on hydrodynamics in shallow areas at regional level (sea level, waves and currents parameters), data about coastal geomorphology (bathymetric profiles, digital terrain models, aerial and satellite image 
collections), and the influence of the shoreline orientation, or coastal structures (Mateescu, 2009). Due to its interactions, the circulation processes in the marine areas are in connection and drives the coastal hydrological processes at once bringing strong inputs to deep offshore areas (Bondar, 1973).

\section{EXPERIMENTAL}

The measurements were performed during the oceanographic expeditions of NIMRD "Grigore Antipa" with "Steaua de Mare" research vessel, over June 2020 and June 2021, in the oceanographic stations network. Data registered in 6 oceanographic stations, 2 stations in Sulina area (S1 and S3), and 4 stations in Sf. Gheorghe area (SG1, SG2, SG3 and SG4) were chosen for analysis (Table 1 and Fig.1).

In addition to the oceanographic expeditions, measurements of currents and flow were performed in July 2020 and June 2021, in the Danube mouths area, to observe the dynamic of the water masses mixing.

Table 1. Coordinates of selected oceanographic stations related to the Danube Delta

\begin{tabular}{|l|c|c|c|}
\hline Station & Longitude & Latitude & Depth (m) \\
\hline S1 & 29.7717 & 45.1439 & 10 \\
\hline S3 & 29.9242 & 45.1228 & 30 \\
\hline SG1 & 29.6364 & 44.8836 & 10 \\
\hline SG2 & 29.6783 & 44.8836 & 20 \\
\hline SG3 & 29.7017 & 44.8836 & 30 \\
\hline SG4 & 29.8529 & 44.8836 & 40 \\
\hline
\end{tabular}

The satellite images taken during the mentioned period were analyzed in parallel with the terrestrial and aerial photo images of the freshwater input (Mateescu et al., 2014).

Thus, the measurements were performed in Sulina, Sf. Gheorghe and Sahalin areas as follows:

- measurements of river discharge on Sulina and Sf. Gheorghe branches,

- current profiles in alignments to the coastal bounded base,

- currents profiles to the western area (the extremity) of Sahalin barrier island,

- UAV photos of entire area.

The cross-sectional currents profiles and flows measurements were carried out with Doppler equipment, ADCP WHS $600 \mathrm{kHz}$ and $1200 \mathrm{kHz}$, using Vsoftware, WinRiver II, and WinADCP dedicated software to data collection and processing. The depths measurements provided by ADCP were validated 
by the Odom CVM hydrographic echosounder served by a Valeport mini-SVP. For positioning, Trimble GeoXH6000 GPS, GNSS Hemisphere S320 and Trimble Juno $\mathrm{C}$ were used. For the graphical representation of data, OceanData View (ODV), and ArcGIS were used (Mateescu et al., 2016).

The currents' data collected in the field were compared with the results of iSWIM forecast, at the surface layer (http://iswim.rmri.ro/maps/maps1.shtml) (Mateescu et al., 2017).

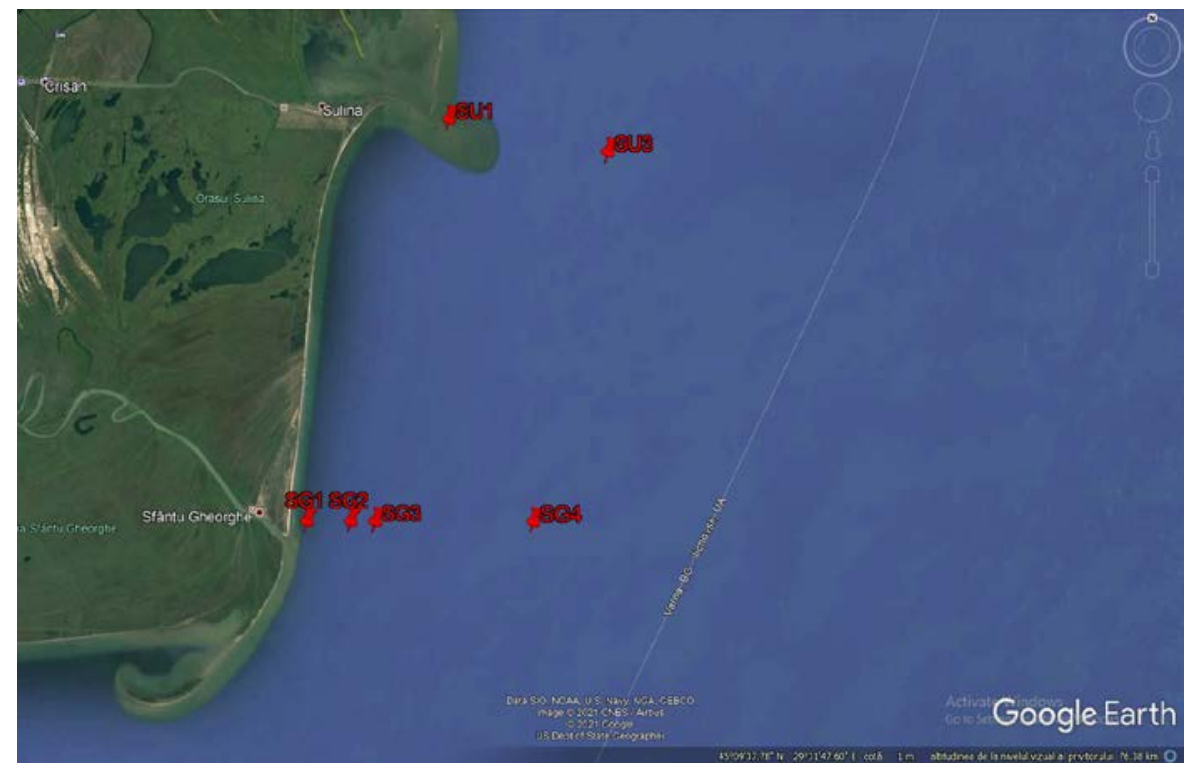

Fig. 1. Monitoring stations network in front of the Danube mouth, represented in Google Earth

\section{RESULTS AND DISCUSSION}

Even if the understanding of evolution of Black Sea physical characteristics, in the current area of interest, is influenced by lack of measurements in the cold season over the last 30 years, the data collected during the summer, can highlight the trends of parameters' variability (temperature and salinity) in the middle layers of water masses (including seasonal thermocline) as well at the surface (until $5 \mathrm{~m}$ depth), in the proximity of the river mouths. These modifications may be key factors in the comparison of hydrodynamic and biogeochemical processes in the coastal area, at regional level, in comparison with the offshore zone (Oguz et al., 1994). Therefore, a pattern of mass transport was be noticed, between the coastal and deep-water areas.

To emphasize the influence of the river plume orientation, two stations were chosen at $10 \mathrm{~m}$ and $30 \mathrm{~m}$ depth, in front of the Danube mouth in Sulina and Sf. Gheorghe sectors. Even if no major change was observed in the depth 
interval of thermocline variation, both sectors of the Danube Delta/mouth show relatively pronounced physical and hydrological differences between the coastal and the offshore area. These differences are determined by the specific hydrological regime of the Romanian Black Sea shelf (the offshore currents influence), the freshwater river discharge, together with the marine thermal regime, being a significant factor in the development of the circulation processes at the scale of the northwestern Black Sea basin (Mateescu, 2009).

The shift in the profile structure in front of the Sulina Branch, station $\mathrm{S} 1$ (at 10m depth) is related to the river hydrological regime and the orientation of the river plume/discharge in 2021, substantial reflected in the CTD recordings on water column of $10 \mathrm{~m}$, due to the placement of the measuring point.

The analysis of hydrological and hydro-chemical changes, between June 2020 and June 2021, based on the comparative graphical analysis of CTD profiles, shows an annual change in temperature and salinity parameters measured in the Danube discharge area, with average values of $3-5{ }^{\circ} \mathrm{C}$ and $4-$ 6 PSU, given by the meteorological-hydrological peculiarities of the two years (Fig. 2).

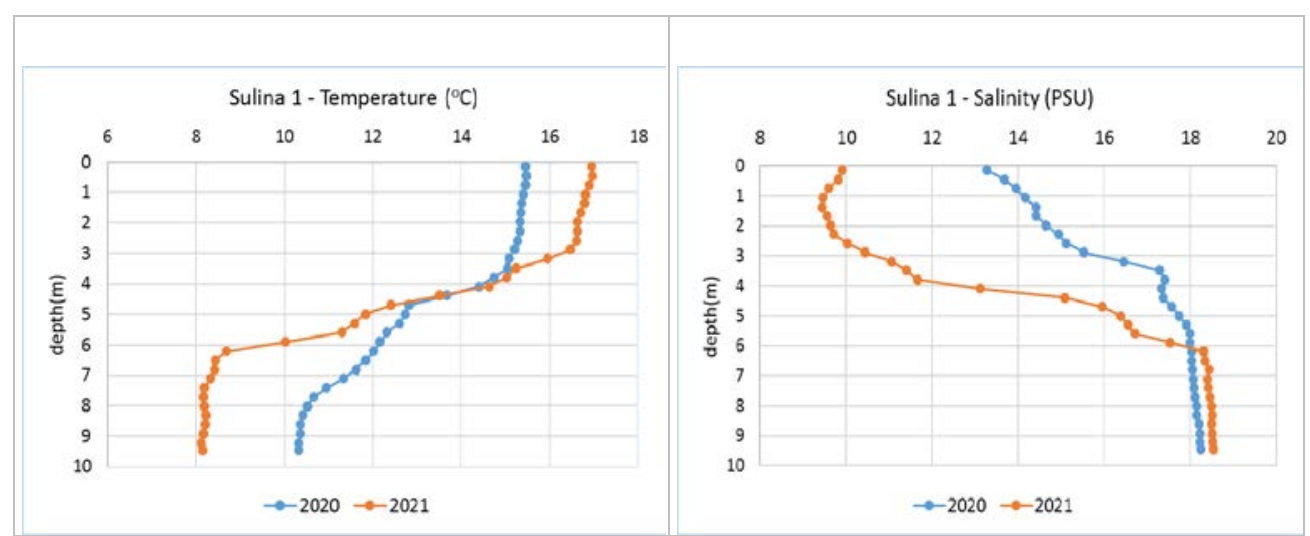

Fig. 2. Temperature and salinity profiles (2020 and 2021) - Sulina, station S1, (10m depth)

The analysis of hydrological and hydro-chemical changes, between June 2020 and June 2021, based on the comparative graphical analysis of CTD profiles, shows an annual change in temperature and salinity parameters measured in the Danube discharge area, with average values of $3-5{ }^{\circ} \mathrm{C}$ and $4-$ 6 PSU, given by the meteorological-hydrological peculiarities of the two years (Fig. 2). The variation interval for both parameters show a low variability within the specified time frame. The atypical values, especially in Sf. Gheorghe, station SG3 (Fig.3), were provided by the southward influence of the freshwater plume from the Sulina branch, driven by a north-west wind, 
very clearly outlined outside the turbulent mixing area, as revealed by the ADCP records (Fig. 4).

The stratification, as well the high speed in the surface layers were emphasized by the currents profile, having insignificant values for the vertical movements.

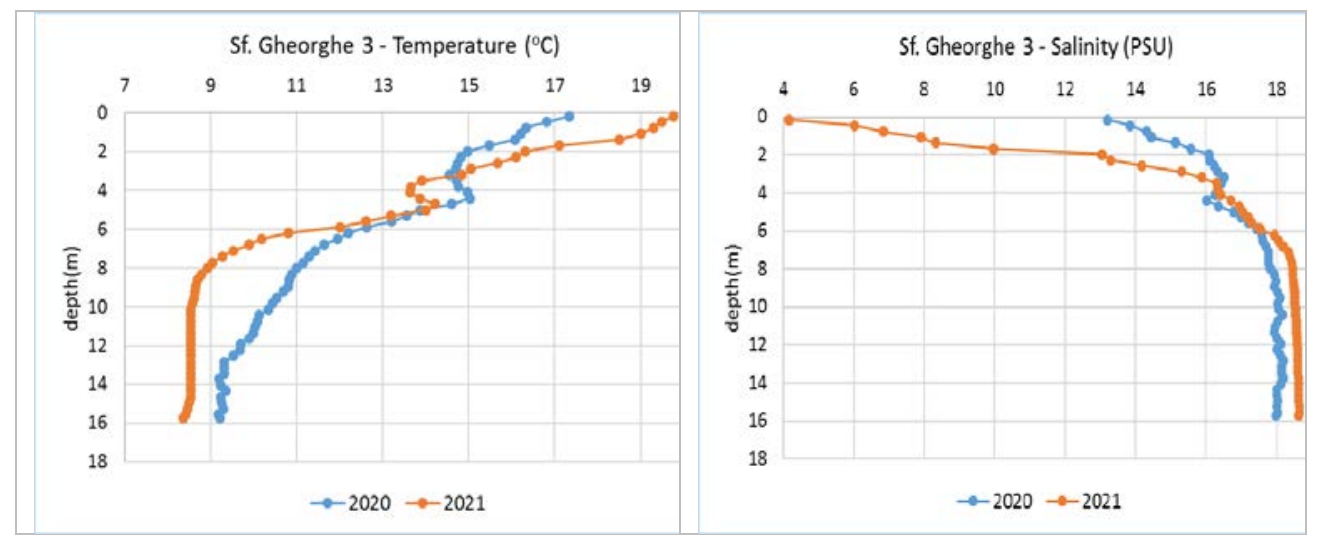

Fig. 3. Temperature and salinity profiles (2020 and 2021),

Sf. Gheorghe, station SG3 (30m depth)

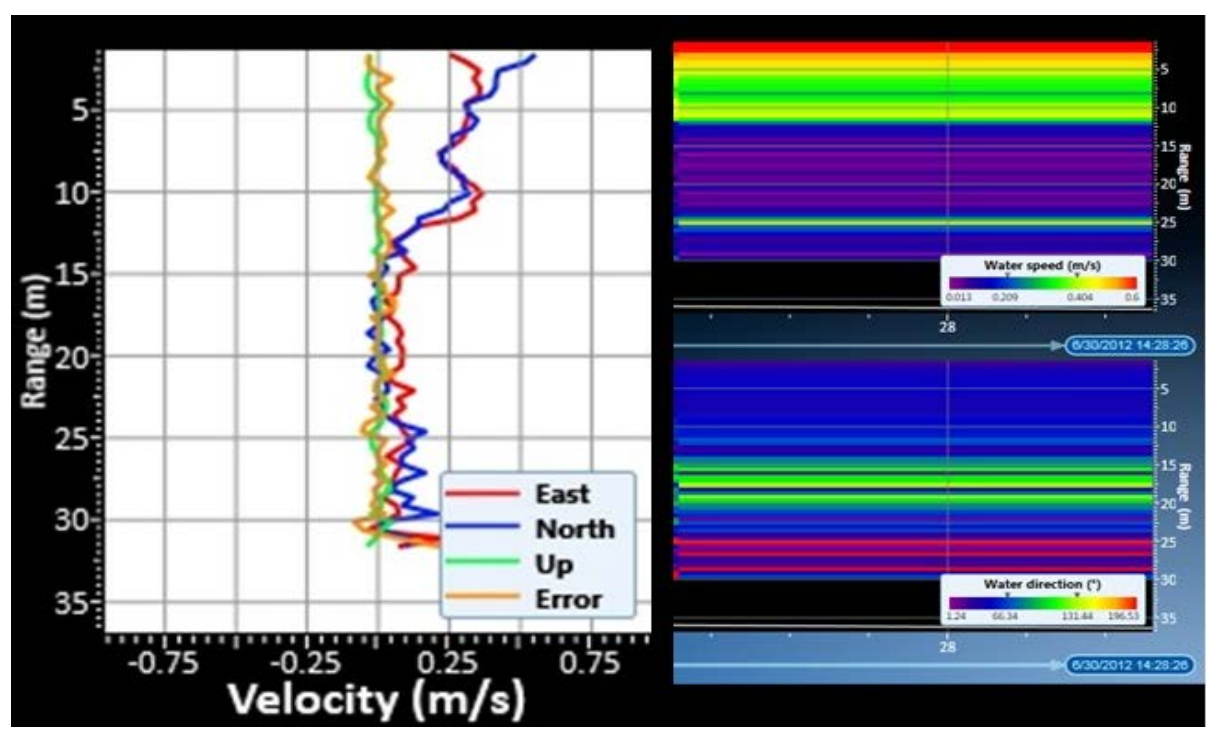

Fig. 4. Surface currents associated to the freshwater discharge, in Sulina area, station S3 (current profile measured on water column, from surface to the 30m depth), represented with V-software

The profiles of the coastal currents, (current speed and direction measured on the water column), in the shallow waters of the Danube Delta over 2020-2021 reveal longitudinal currents development with impact on 
sediment transport and water mixing in the proximity of sea-land interface.

The measurement sessions in the Sahalin area even if were performed with different instruments, (WHS600 in June 2020 and WHS1200 in 2021) were carried out in the similar meteorological and hydrological conditions in both years, respectively wind conditions of about $30 \mathrm{~km} / \mathrm{h}$ from north sector (NE in 2020 and NW in 2021), in the context of swell waves of $0.5 \mathrm{~m}$ high from NE. The currents measurements, were positioned with the GPS transversely on the shoreline and, in two cases, transversely on the freshwater plume (in the front of freshwater flow), to provide data on deltaic coastal hydrodynamics: flow velocity components, depth, the transverse distance between each vector, the total distance of the cross section and the geographical position of each vector, for a depth range of $0.5-21 \mathrm{~m}$. Regarding the distribution of coastal currents, the results showed a significant influence of the currents induced by the fresh water discharge of the Danube branches, as well as the influence of wind intensity at the sea-atmosphere interface. The ADCP section at Sulina bar provides an image of the turbulent mixing accentuated at the freshwater-saltwater interface (Fig.5).

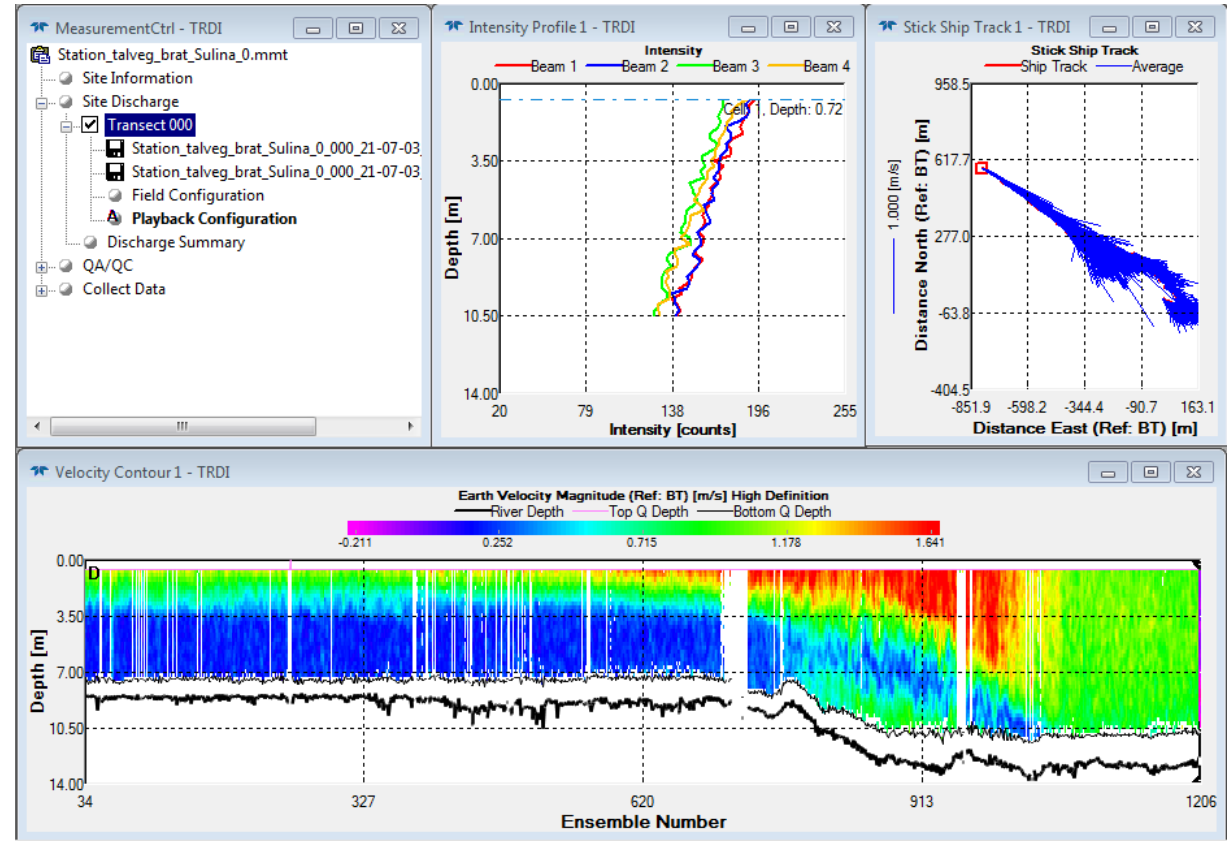

Fig. 5. Currents profile taken with ADCP, on the thalweg of Sulina Channel, in the discharge area, July 3, 2021- WinRiver II software

For a clearer view of the currents distribution in Sulina shore sector, the currents parameters were measured in the area of Sulina beach, to the south of the navigable channel jetties, an anticyclonic current induced by these marine obstacles being observed (Fig.6). 


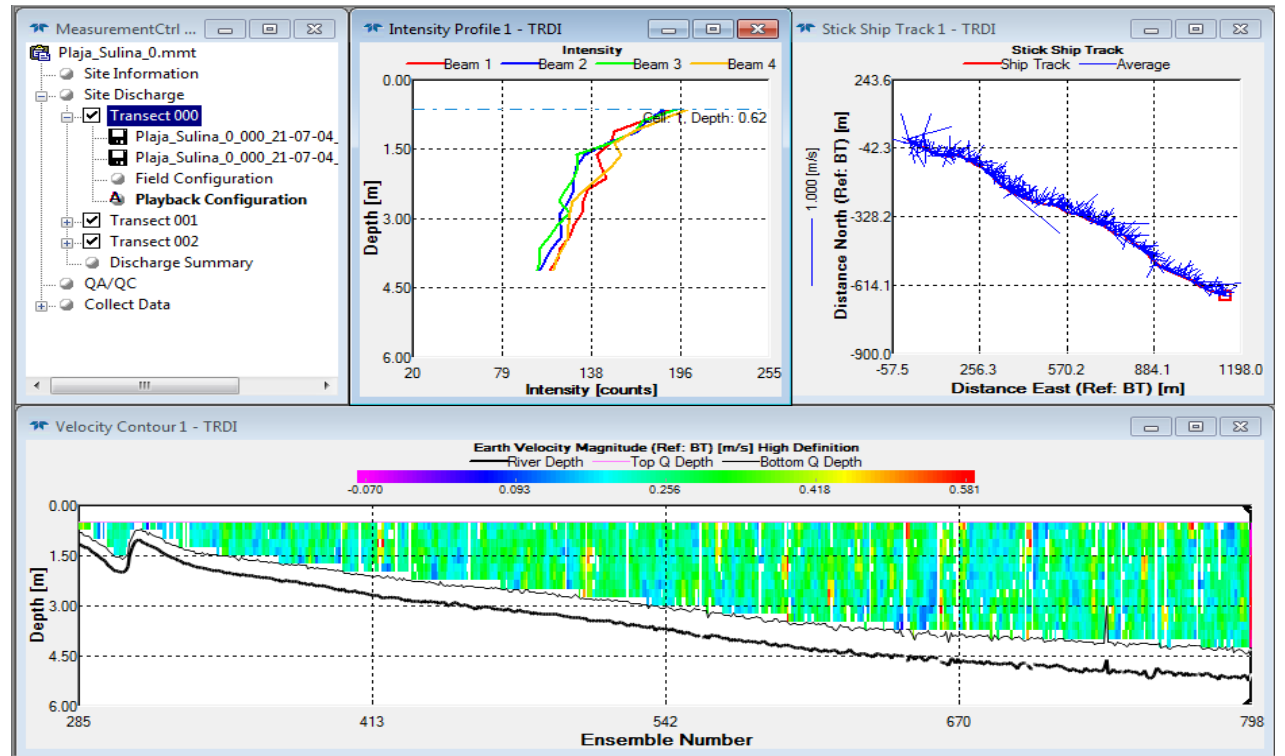

Fig. 6. Current profile registered to the north of Sulina beach, July 4, 2021currents directions revealed anticyclonic circulation by ADCP's dedicated WinRiver II Software's, the ship track window

The velocity profiles through the freshwater front, in the best distribution on the vertical and horizontal section, reveal a small influence in the surface layer, maintaining a relatively uniform distribution, although the measurement was performed in areas with high turbulence and intense sediments transport, which generally should cause problems in ADCP measurement (Fig.8).

Also, the flow at the southern extremity of the Sahalin barrier island is very turbulent producing a series of radial submerged bars. In Sf. Gheorghe Sahalin sector the measurements were affected by the hydrological conditions characterized by high, turbulent waters, loaded with sediment, and a strong atmospheric instability with intense wind of $20-30 \mathrm{~km} / \mathrm{h}$ from the NW and NE direction, with quantitatively significant rain fall (Fig.9). The measurements on the sea and the river were approached flexibly, depending on the different natural obstacles: the submerge bar and the Sahalin barrier island, the wind direction, the existence of "shadow" areas in the propagation of the wind waves, the freshwater flow input into the sea with an average measured value of $1900 \mathrm{~m}^{3} / \mathrm{s}$ at Sf. Gheorghe mouth (corresponding to a quota of $+30 \mathrm{~cm}$ at the Dobrogea Littoral Water Basin Administration (ABADL) Station. This freshwater input has a significant influence in attenuation of the wave field in the adjacent sections, close to the Danube mouth (Fig.7). 


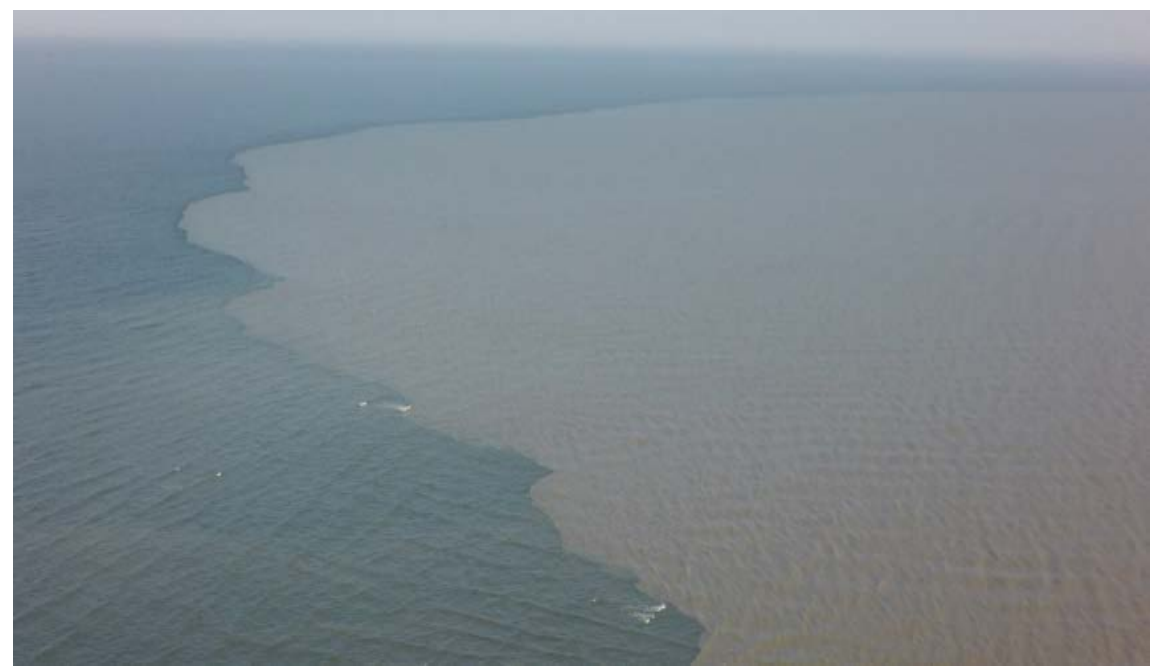

Fig. 7. The freshwater plume (loaded with suspended sediment) extended into the sea, $1 \mathrm{Km}$ upstream to the Belt Canal: the flow of the Sf. Gheorghe branch, July 7, 2021

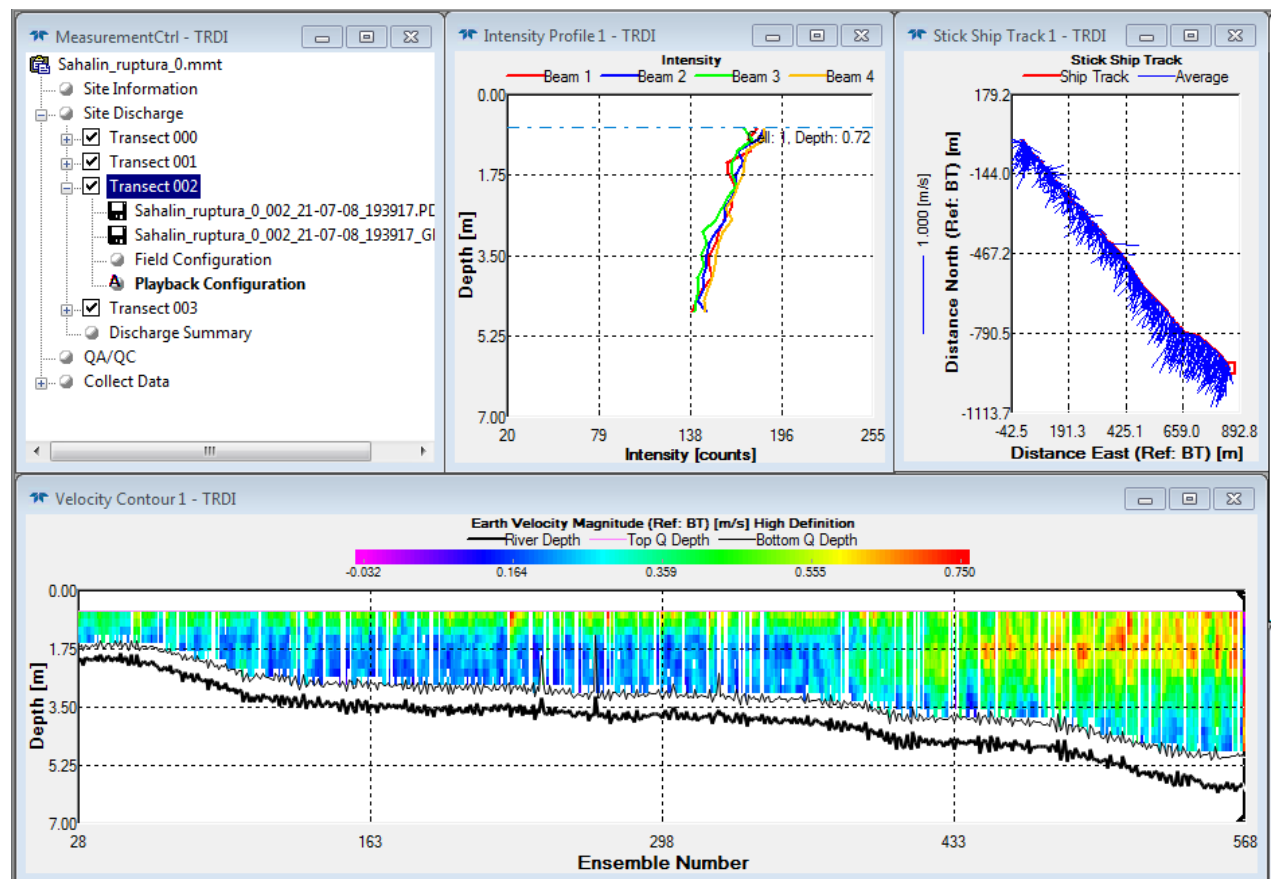

Fig. 8. Current profile measured with ADCP to the north of Sahalin, and at the south of the freshwater discharge on July 8, 2021, represented with WinRiver II Software 


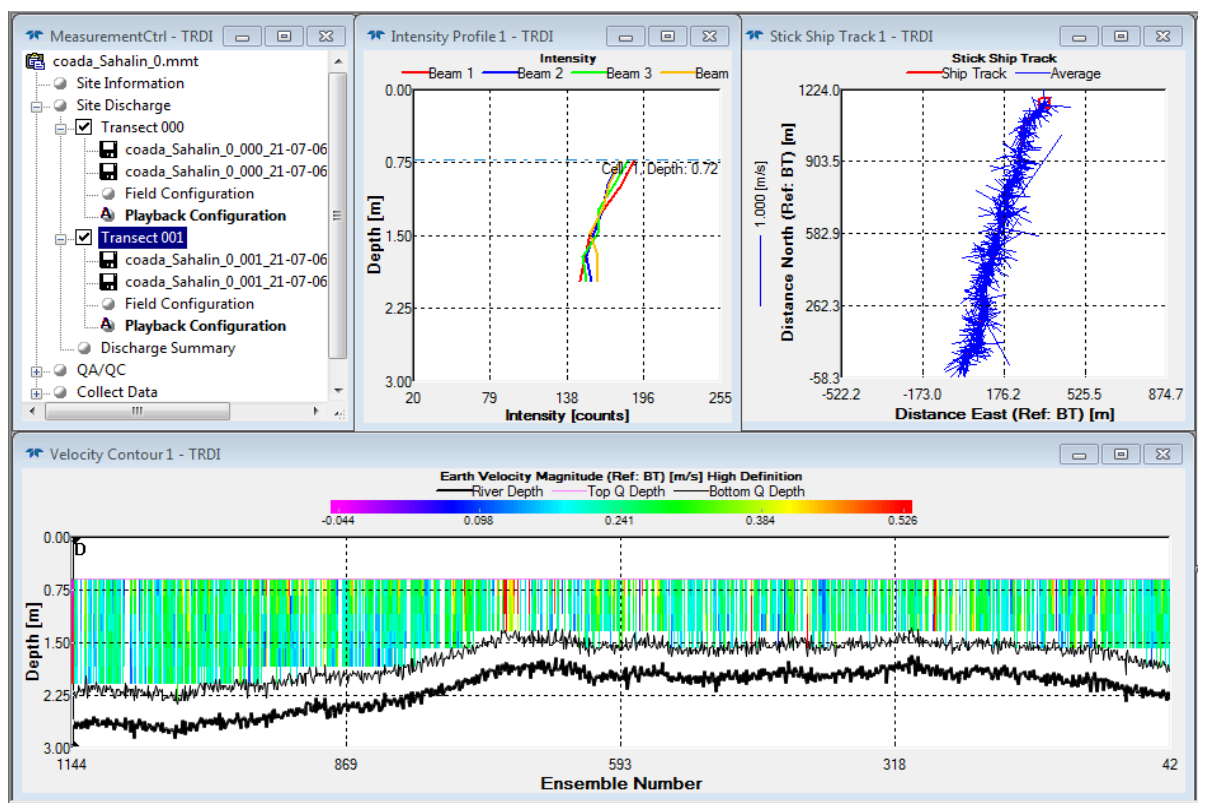

Fig. 9. Current profile measured with ADCP to the southern extremity of Sahalin, section through the freshwater flow on July 6, 2021

The measurements were carried out to capture a wide anticyclonic current induced by the freshwater plume propagated along the Sahalin Island, in order to validate the results of the iSWIM Integrated Service for Water Quality Monitoring, based on MOHID model (Vlasceanu et al., 2019) (http://iswim.rmri.ro/) (Fig.10).

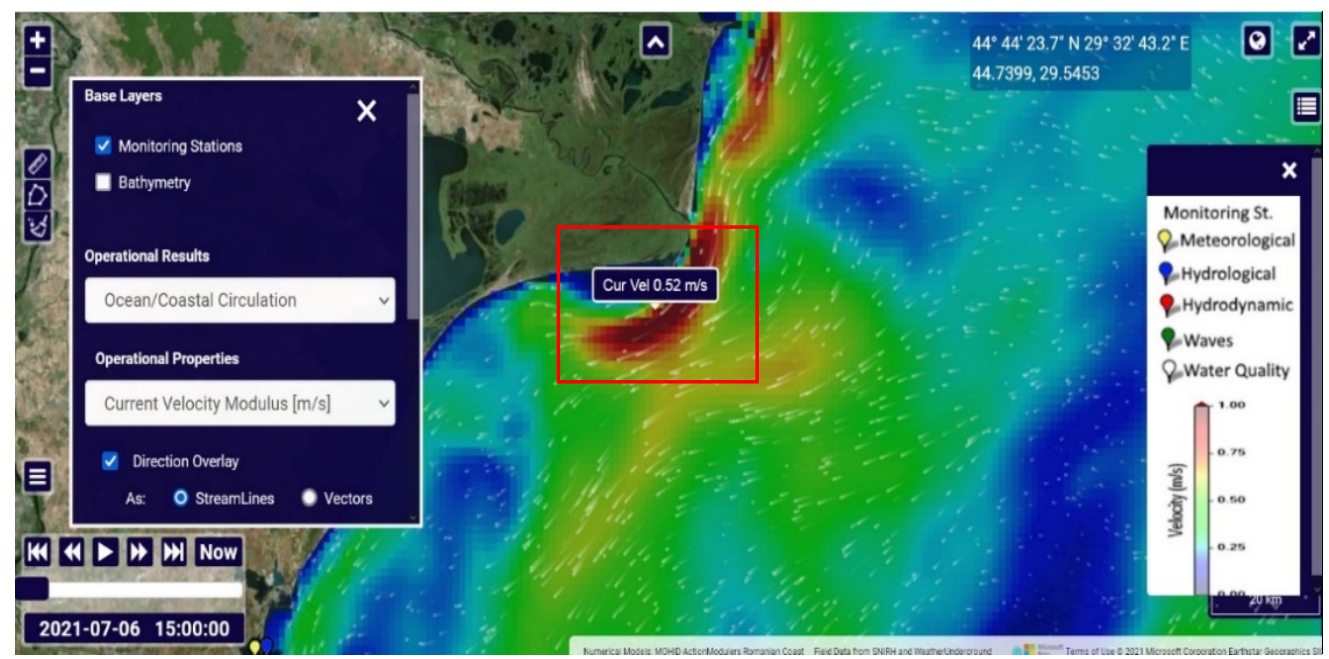

Fig. 10. MOHID model current distribution on July 06, 2021, 15.00h, iSWIM forecast, (http://iswim.rmri.ro/maps/maps1.shtml) - current velocity value of $0.52 \mathrm{~m} / \mathrm{s}$ at the southern extremity of Sahalin barrier island 
The maximum currents velocity measured in the coastal area, and especially in the southern part of the Sahalin barrier island was $1.1 \mathrm{~m} / \mathrm{s}$, revealing the intensity of hydrodynamic processes in the Danube discharge area (Fig.11). The intense mixing processes of the water masses from this area as well as the hydro morphological processes in the adjacent coastal zone, induce the accumulation processes in the southern extremity of Sahalin barrier island, as an effect of erosional processes from the northern and central area of the island. (Fig.12).

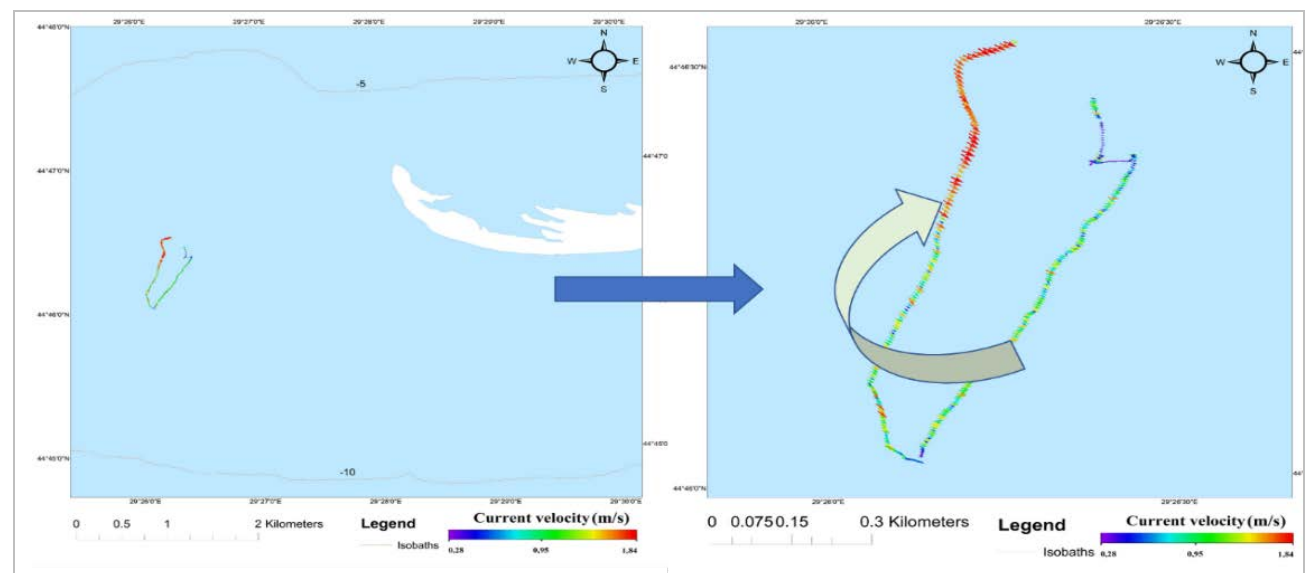

Fig. 11. Average velocity of surface currents, represented in ArcGIS software, based on ADCP measurement, near the south extremity of Sahalin, July 6, 2021

Two water fronts propagated from both sides of the Sahalin barrier island, mixed at its extremity, were measured in 2020, emphasizing an intersection of two currents induced by two directional waves' fields (Fig.13 ship track window).
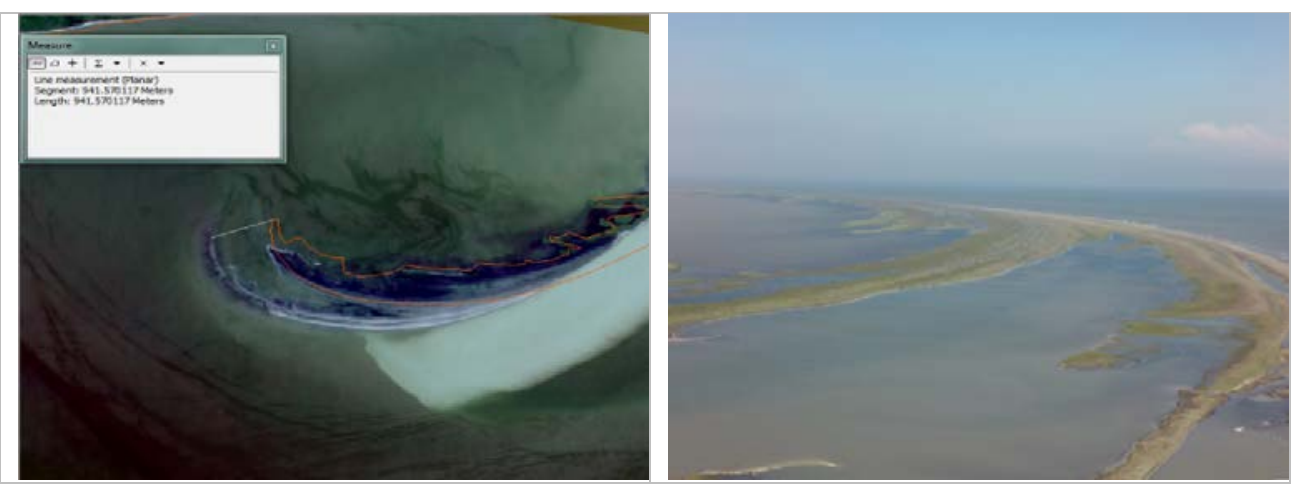

Fig. 12. Satellite image PLANET (represented in ArcGIS, 3m resolution/pixel): enlargement of the Sahalin barrier island by $941 \mathrm{~m}$ in 10 years (June 23, 2021, vs. April 2011) and UAV photo of the "Sahalin tail" taken before the current measurement’s session - July 6, 2021 


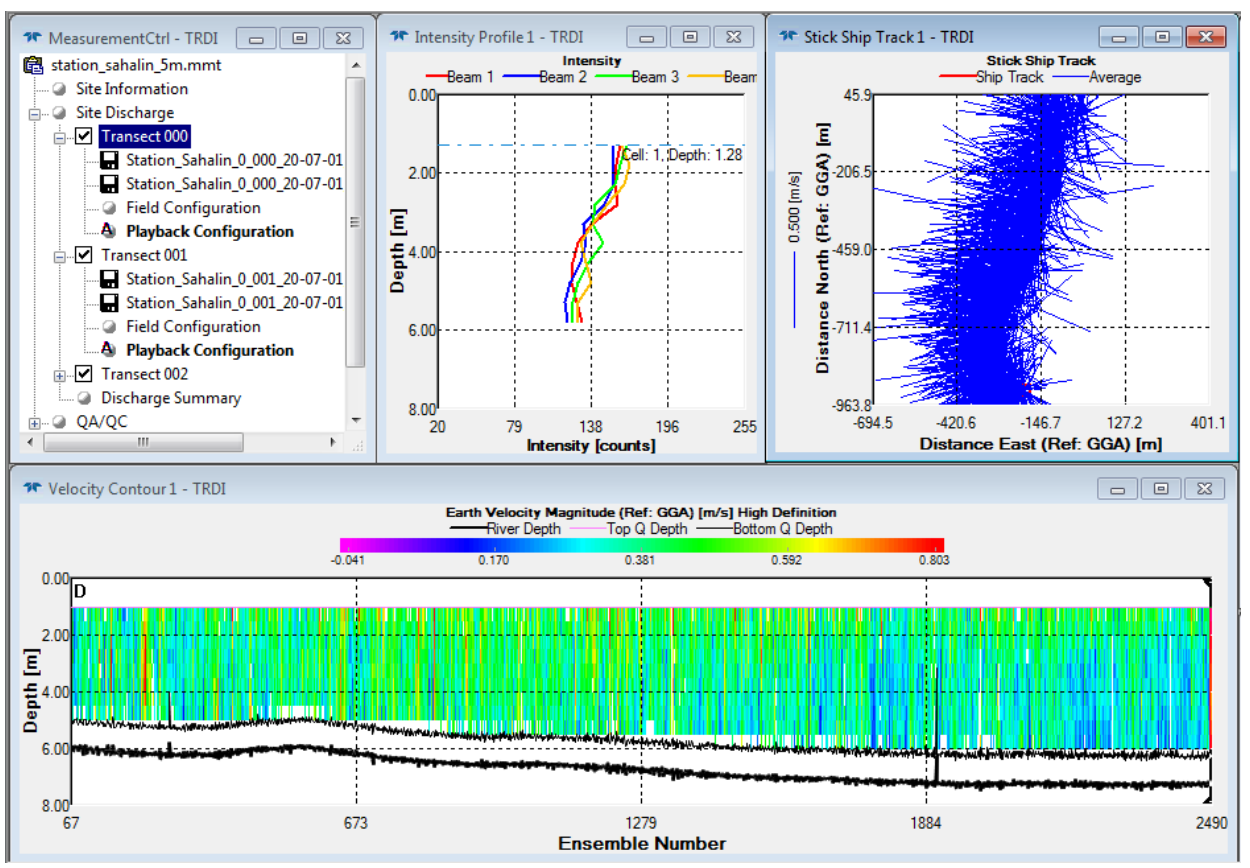

Fig. 13. Current Section taken with ADCP WHS600 near the southern extremity of Sahalin, and to the south of Sf. Gheorghe Branch, July 1, 2020 -

WinRiver II Software

The study of the interference area between two waves fields generated by the river flow and wind-induced hydrological processes may produce a qualitative estimation of the mixing processes near the coast, unique in the context of the asymmetric shoreline configuration of the deltaic region. (Giosan et al., 2005).

\section{CONCLUSIONS}

The assessment of the spatial distribution of the hydro-geomorphological parameters on the Danube Delta's coastal area requires scientific corroboration of in-situ measurements with remote sensing or modelled data. The evaluation of the coastal hydrodynamics variability influenced by the river discharge in a complex configuration of the natural and built shore of the northern Romanian coast can reveal the double-sense interactions between the coastal and deep-sea water masses.

The comparative analysis of the hydrological variability can provide a better understanding of the coastal and marine physical and chemical parameters regarding the mixing processes in the Danube Delta area, but it will require a complex approach and consideration of the climate change influences at regional level, in the last decades. 
Acknowledgement. The work of Elena Vlasceanu was supported by the project ANTREPRENORDOC, in the framework of Human Resources Development Operational Programme 2014-2020, financed from the European Social Fund under the contract number 36355/23.05.2019 HRD OP /380/6/13 - SMIS Code: 123847.The work of Eugen RUSU was carried out in the framework of the research project DREAM (Dynamics of the REsources and technological Advance in harvesting Marine renewable energy), supported by the Romanian Executive Agency for Higher Education, Research, Development and Innovation Funding - UEFISCDI, grant number PN-III-P4-ID-PCE-2020-0008”. The work of Razvan Mateescu was supported by the project PN19260101, Study of the dynamics of physical and hydro-geo-morphological processes to assess the marine and coastal area risks and vulnerabilities in the context of climate changes and anthropogenic pressures (45N/2019).

\section{REFERENCES}

Bondar C., (1973), Black Sea in the area of the Romanian coast, Bucharest, Institute of Meteorology and Hydrology, 516 pp. (In Romanian).

Giosan L., Donnelly J.P., Vespremeanu E., Bhattacharya J.P., Olariu C., Buonaiuto F. S., (2005), River Delta Morphodynamics: Examples from the Danube Delta, River-Deltas Concepts, Models and Examples, SEPM (Society for Sedimentary Geology), Special Publication 83: 393-411.

Niculescu D., Vlasceanu E., Petrila M., Mateescu R., Omer I., Dimache A., Iancu I., (2017), Unmanned aerial vehicle (UAV) technology in monitoring of coastal cliffs, J Environ Prot Ecol, 18 (3):1202-1212.

Mateescu R., Vlasceanu E., Niculescu N., Brownscheig F., Fernandez R., Brito D., (2017). Mamaia Beach Bathing Water Quality Forecast System, AGIR Bulletin, 4:72-76. (In Romanian).

Mateescu R., (2009), Hydrodynamics of the Romanian marine and coastal area, Bucharest, University Publishing House (In Romanian).

Mateescu R., Niculescu D., Vlasceanu E., Mihailov E., (2016). Specific capacities of earth observation technologies, created within the COSMOMAR competence center, for sustainably development of Romanian marine and coastal areas, AGIR Bulletin, Supplement 3: 98103. (In Romanian).

Mateescu R.D., Spinu A., Buga L., Niculescu D., Mihailov E., Vlasceanu E., (2014), Remote sensing applications for the ecosystem-based management process implementation in the Romanian Black Sea Coastal Zone, Baltic International Symposium (BALTIC), 2014 IEEE/OES, 27-29 May 2014, Tallinn, Estonia https://ieeexplore.ieee.org/document/6887837. 
Oguz T., Aubrey D.G., Latun VS., Demirov E., L Koveshnikov, HI Sur, V Diaconu, S Besiktepe, Murat Duman, R Limeburner, V Eremeev (1994), Mesoscale circulation and thermohaline structure of the Black Sea observed during HydroBlack '91. Deep Sea Research Part I: Oceanographic Research Papers, 41 (4): 603-628.

Vlasceanu E., Buzbuchi N., (2019), Application of numerical hydrodynamic models in the study of the marine currents in Romanian Black Sea area, J Environ Prot Ecol, 20 (4):1769-1776. 